\title{
Bernard Herencia, Les Éphémérides du citoyen et les Nouvelles Éphémérides économiques 1765-1788. Documents et table complète
}

\section{Simón Gallegos Gabilondo}

\section{(2) OpenEdition \\ Journals}

\section{Edizione digitale}

URL: http://journals.openedition.org/studifrancesi/455

DOI: $10.4000 /$ studifrancesi.455

ISSN: 2421-5856

\section{Editore}

Rosenberg \& Sellier

\section{Edizione cartacea}

Data di pubblicazione: 1 aprile 2015

Paginazione: 149

ISSN: 0039-2944

\section{Notizia bibliografica digitale}

Simón Gallegos Gabilondo, « Bernard Herencia, Les Éphémérides du citoyen et les Nouvelles

Éphémérides économiques 1765-1788. Documents et table complète », Studi Francesi [Online], 175 (LIX I

I) | 2015, online dal 01 avril 2015, consultato il 17 septembre 2020. URL : http://

journals.openedition.org/studifrancesi/455; DOI : https://doi.org/10.4000/studifrancesi.455

Questo documento è stato generato automaticamente il 17 settembre 2020.

\section{cc) $($ ) $\ominus$}

Studi Francesi è distribuita con Licenza Creative Commons Attribuzione - Non commerciale - Non opere derivate 4.0 Internazionale. 


\title{
Bernard Herencia, Les Éphémérides du citoyen et les Nouvelles Éphémérides économiques 1765-1788. Documents et table complète
}

\author{
Simón Gallegos Gabilondo
}

\section{NOTIZIA}

BERNARD HERENCIA, Les Éphémérides du citoyen et les Nouvelles Éphémérides économiques 1765-1788. Documents et table complète, Ferney-Voltaire, «Centre international d'étude du XVIII ${ }^{\mathrm{e}}$ siècle», 2014, pp. 418.

1 Il presente lavoro costituisce uno strumento inedito proposto al pubblico per lo studio di uno dei principali organi di stampa impegnati in un ampio dibattito pubblico tra i cui effetti vi è la nascita dell'economia politica. Le Éphémérides catalogate ed analizzate nel libro che presentiamo rientrano nella proliferazione della pubblicistica economica francese verificatasi nella seconda metà del xviII secolo, un fenomeno culturale la cui ampiezza e influenza vanno ben oltre la sfera dell'economia dell'ancien régime. Effettivamente, quest'immenso corpus del pensiero fisiocratico si presenta, non soltanto al lettore ma anche allo studioso, come un labirinto formato da ventiduemila pagine di giornali attraversati da strade che s'interrompono all'improvviso.

Fondate da Nicolas Baudeau, antischiavista convertitosi alla fisiocrazia, le Éphémérides diventano una macchina editoriale al servizio della diffusione della dottrina economica elaborata da François Quesnay. Gli argomenti trattati abbracciano gli ambiti più svariati delle lettere e delle scienze, spesso orientati verso questioni d'attualità che alimentano il pensiero economico nel senso più ampio, attraverso una riflessione su temi come il bilancio dello stato, il commercio del frumento, l'industria mineraria, le colonie francesi nelle Indie, il diritto naturale romano, lo spopolamento delle campagne, la 
storia della navigazione, la proprietà della terra, l'istruzione pubblica, il dispotismo cinese e la storia del continente americano, passando per la pubblicazione di lettere di lettori, recensioni di libri e rubriche diverse. I numerosi collaboratori di quest'impresa pubblicistica, tra cui diverse firme illustri, aspirano a formare cittadini attraverso l'educazione dell'opinione pubblica, in uno slancio riformatore costruito in una trama tutt'altro che lineare e priva d'incognite. Oltre a un indice esaustivo di tutti i contributi, il volume contiene una prefazione di Philippe Steiner (pp. VII-VIII), una presentazione dell'autore (pp. IX-XXIII) e degli strumenti di ricerca di agile consultazione (Concordances graphologiques; La nomenclature lettrée et ses sources; Auteurs désignés par un pseudonyme, un surnom, un titre, un état ou une abréviation; Avis des libraires et avis aux souscripteurs, Avertissements, notice, table raisonnée et préface; Liste des articles et des suites des articles; Index des noms cités). Bisogna infine segnalare che tutti i tomi digitalizzati delle Éphémérides sono disponibili online (bernard-herencia.com/ephemerides).

Rimane forse il rischio di confondere l'indicizzabile con l'intelligibile, e di vietare l'accesso ai luoghi dove ci si perde. 